Original article

\title{
Bioimpedance spectroscopy measurements of phase angle and height for age are predictive of outcome in children following surgery for congenital heart disease
}

\author{
L.V. Marino ${ }^{\text {a, }{ }^{*}, \text { R. Meyer }}{ }^{b}$, M. Johnson ${ }^{\text {c, d }}$, C. Newell ${ }^{\mathrm{d}}$, C. Johnstone ${ }^{\mathrm{a}}$, A. Magee ${ }^{\mathrm{e}}$, \\ K. Sykes ${ }^{\text {f }}$, S.A. Wootton ${ }^{\mathrm{d}, 1}$, J.V. Pappachan ${ }^{\mathrm{f}, 1}$ \\ ${ }^{a}$ Department of Dietetics/SLT, University Hospital Southampton NHS Foundation Trust, UK \\ b Department of Paediatrics, Imperial College London, UK \\ c Department of Neonatal Medicine, University Hospital Southampton NHS Foundation Trust, UK \\ ${ }^{\mathrm{d}}$ NIHR Biomedical Research Centre Southampton, University Hospital Southampton NHS Foundation Trust and the University of Southampton, UK \\ e Paediatric Cardiology, University Hospital Southampton NHS Foundation Trust, UK \\ ${ }^{\mathrm{f}}$ Paediatric Intensive Care Unit, University Hospital Southampton NHS Foundation Trust, UK
}

\section{A R T I C L E I N F O}

\section{Article history:}

Received 13 February 2017

Accepted 20 June 2017

\section{Keywords:}

Nutrition

Phase angle

Bioelectrical impendence

Congenital heart disease

\begin{abstract}
S U M M A R Y
Objective: Children with congenital heart disease (CHD) are often growth restricted (low weight- and/or height-for-age) which may increase risk of poor post operative resilience. Bioelectrical impedance spectroscopy (BIS) has been used to determine body composition in different clinical settings and has been shown to mark differences in nutritional state and clinical outcome. In disease conditions were fluid is not normally distributed it is proposed that raw impedance values and BIS derived phase-angle may serve as prognostic indicators of clinical outcome. We sought to describe the relationship between nutritional status, phase-angle and post-operative outcomes in children with congenital heart disease. Design: Single centre prospective cohort study.

Setting: Paediatric Intensive Care Unit (PICU), Southampton Children's Hospital.

Patients: 122 children with CHD following cardiac surgery (March 2015-April 2016). Outcome variables included growth, mechanical-ventilation, PICU length of stay (PICU-LOS) and phase-angle at $50 \mathrm{~Hz}$. Measurements and main results: BIS measurements were taken before and on the day of surgery (day 0 ), day 2 post-operatively and on discharge from hospital. Pre-operative moderate malnutrition defined as height-for-age-z-score (HAZ) $\leq-2$ was observed in $28.5 \%$ of infants and $20.6 \%$ of children. Regression analysis was used to investigate the relationship between phase-angle, HAZ and clinical outcomes. Moderate-malnutrition (HAZ $\leq-2$ ) was associated with an increased PICU-LOS (odds ratios (OR) with $95 \%$ confidence interval: $1.8 ; 1.1-2.7, \mathrm{p}=0.008)$ whilst a low phase-angle $\left(\leq 2.7^{\circ}\right.$ on day 2 was associated with longer PICU-LOS (OR 7.8; 2.7-22.45, $\mathrm{p}<0.001)$ ); When the model was adjusted for age, known risk factors and length of surgery, $\mathrm{HAZ} \leq-2$ and phase-angle $\leq 2.7^{\circ}$ on day 2 were associated with longer PICU-LOS ( $\mathrm{p}=0.001$ and $\mathrm{p}=0.04$ respectively) and together explained $81.7 \%$ of the variability in PICULOS.

Conclusions: Moderate malnutrition $(\mathrm{HAZ} \leq-2)$ in infants and children undergoing cardiac surgery is associated with longer PICU-LOS. Post-operative measures of BIS phase angle may further improve our ability to identifying hose children with an increased risk of prolonged PICU-LOS compared to using preoperative anthropometry alone.
\end{abstract}

๑) 2017 Elsevier Ltd and European Society for Clinical Nutrition and Metabolism. All rights reserved.

\footnotetext{
* Corresponding author. University Hospital Southampton NHS Foundation Trust, Southampton, S016 6YD, UK. E-mail address: luise.marino@uhs.nhs.uk (L.V. Marino).

1 Joint last author.
} 


\section{What we know:}

- A low phase angle is associated with poorer clinical outcomes.

- A low phase angle is associated with poor nutritional status.

- A low phase angle may preceded anthropometrical changes.

\section{What this study adds:}

- A post-operative phase angle of $<2.7^{\circ}$ on is associated with poorer clinical outcomes in children with congenital heart disease.

- A low phase angle may add a sensitivity and specificity to predicting those children who may have poor post operative resilience.

\section{Introduction}

At present there are few reliable surrogate measures for identifying those children at risk of poorer clinical outcomes following surgery for congenital heart disease (CHD). Recent work suggests undernourished children are at risk of prolonged paediatric intensive care length of stay (PICU-LOS) [1,2], however, the use of pre-operative anthropometrical measures to predict those at risk of prolonged PICU-LOS may not be sensitive enough to adequately identify all children at risk [3].

Bioelectrical impedance spectroscopy (BIS) has been used to estimate body composition in a variety of clinical settings and more recently to measure alterations in cell membrane integrity and total body water in order to predict clinical risk $[4,5]$. Phase angle depends on the opposition to the flow of electrical current (resistance) and the effect of the capacitive ability of cell membranes to impede the current (reactance). Phase angle is negatively associated with resistance and positively associated with reactance and has been used to quantify cell membrane integrity (reactance) and the extent of fluid redistribution between intra- and extracellular fluid compartments (resistance). Changes in phase angle have also been shown to precede anthropometrical changes such as weight loss and as such may be an early marker of change in an individual's overall resilience $[4,6,7]$.

Phase angle is usually lower than normal in disease states as a result of the influence of infection, inflammation or disease. As BIS is non-expensive, portable, easy to use and non-invasive there has been growing interest in the use of BIS-derived measures of phase angle in an ICU setting [8]. In adults undergoing cardiac surgery a low pre-operative phase angle $\left(<5.37^{\circ}\right)$ was associated with undernutrition and an increased risk of prolonged post-operative intensive care and hospital stay [9]. Shime and colleagues [7] found that a greater than $20 \%$ reduction in impedance after surgery in children with CHD was associated with poorer outcomes [10] and Azavedo and colleagues [8] found that lower measures of reactance $(\mathrm{Xc})$ and resistance $(\mathrm{R})$ were found in critically ill children who did not survive their stay on PICU compared to those who were discharged [11].

Low phase angle values have been shown to be predictive of functional reserves $[4,6,7]$ and resilience in a variety of other clinical conditions [12-14] and have been shown to be related to nutritional status in children [15]. A low phase angle may be indicative of $i$ ) changes to cellular permeability and tissue hydration, with an increased extracellular fluid component or, ii) lower cell mass e.g. muscle mass and total body cell mass seen in malnutrition $[4,6]$.

The aim was to determine whether there was a relationship between malnutrition, BIS-phase angle and early post-operative outcomes relating to PICU-LOS, in children following cardiac surgery.

\section{Methods and materials}

\subsection{Study design and patient population}

This study was approved and NHS ethics committee (West Midlands, reference $15 / \mathrm{WM} / 0020$ ). Children (0-16 years) with CHD undergoing cardiac surgery were prospectively enrolled (March 2015-April 2016) at a single tertiary centre. Infants were defined as those $\leq 12$ months age and children $\geq 1$ year -16 years of age. BIS measurements were collected at baseline (day before surgery), on post-operative days 0 and 2, and at discharge from hospital. Exclusion criteria included children with a permanent pacemaker and those receiving corticosteroids.

\subsection{Definitions of moderate malnutrition}

We are not aware of any other literature defining malnutrition in infants/ children with cardiac disease so chose to use $\mathrm{Z}$ scores to classify growth and as such chose to use WHO classification of moderate malnutrition $<-2 \mathrm{z}$ scores. A priori we did not exclude those children with known growth perturbations such as trisomy 21 or Di-George syndrome (22q.11), as we were primarily interested in the relationship of impedance and phase angle and postoperative clinical outcomes in all children undergoing cardiac surgery. However, there are limitations to this approach as growth in children with CHD may be different to that of a healthy population.

Z-scores were calculated using WHO Anthro software version 3.3.3 2011 [16] for participants $\leq 5$ years and WHO AnthroPlus 3.2 [17] for those $\geq 5$ years. WHO growth reference interpretation of cut offs for malnutrition were used. Moderate malnutrition was defined as a height-for-age or weight for height $\leq-2$ z-scores below the mean of the WHO child growth standards [18]. In this study, we chose to use height for age $<-2$ as a cut off value for moderate malnutrition as it represented persistently poor or chronic state of malnutrition.

\subsection{BIS measurements and anthropometry}

BIS is validated for use in a wide range of paediatric patients particularly with respect to body composition [19] Lower phase angles have been associated with poorer outcomes $[4,15]$.

BIS measurements were made using ImpediMedSFB7 (Pinkenba, QLD 4008 Australia), a single-channel tetra-polar device able to measure resistance and reactance across 256 frequencies. The machine was calibrated before use with a circuit of known impedance provided by the manufacturer. Measurements were taken in triplicate, with the mean used in the analysis. Measurements were conducted using a standard tetrapolar electrodes distribution, on palms of hands and soles of feet, supine with arms and legs apart (Fig. 1). BIS measurements were completed in unfasted subjects. BIS data files were processed using specialist software (Bioimp, ImpediMed), with data points rejected if they met any of the following criteria; i) positive $\mathrm{X}$ centre $(\mathrm{Xc})$ values, ii) negative resistance values. Phase angle at a current frequency of $50 \mathrm{~Hz}$ was used for analysis [11]. 

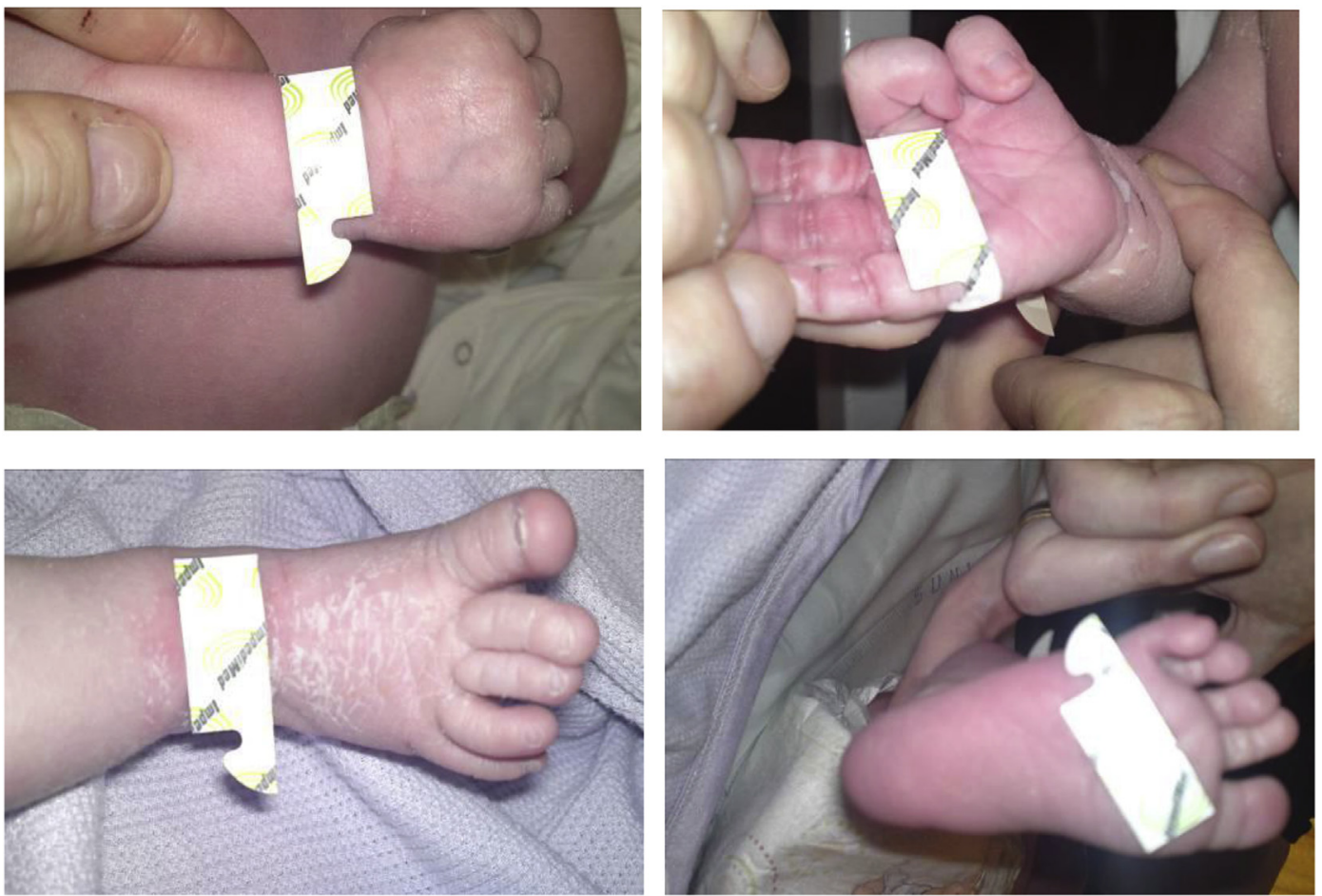

Fig. 1. BIS electrode placement.

Anthropological measurements were performed and recorded in accordance with local Standardised Operating Procedures and World Health Organisation (WHO) guidelines [18]. Infants $\leq 1$ year were weighed naked and children $\geq 1$ year with minimal clothing; weight was measured to the nearest $0.1 \mathrm{~kg}$ using a digital scale. Recumbent length was measured to the nearest $0.1 \mathrm{~cm}$ for all children $\leq 2$ years using an infantometer (Seca 416; Birmingham, UK) and standing in older children under a stadiometer (Seca 213: Birmingham, UK).

\subsection{Post-operative fluid management}

In the first $12-24 \mathrm{~h}$ post cardiac surgery patients are typically fluid restricted to $2-3 \mathrm{ml} / \mathrm{kg} / \mathrm{hr}$ (48-72 $\mathrm{ml} / \mathrm{kg} /$ day), which depending on fluid balance and other clinical measures is usually liberalised to a maximum of $4 \mathrm{ml} / \mathrm{kg} / \mathrm{h}$ (96 ml $/ \mathrm{kg} / \mathrm{day})$ on consecutive days. The use of diuretics is individualised depending on urine output and cumulative fluid balance.

\subsection{Patient and operation characteristics}

Data regarding patient characteristics were collected, including age, gender, surgical risk measured by risk adjusted cardiac heart surgery -1 score (RACHS-1) [20], inflammatory response, as Creactive protein (CRP) $\geq 5 \mathrm{mg} / \mathrm{l}$, hypoalbuminaemia (albumin $\leq 39 \mathrm{~g} /$ 1), type of cardiac lesion and paediatric index mortality risk-2 (PIMS2) [20]. Risk factors used in the analysis included RACHS-1, PIMS2, fluid balance, cardiopulmonary bypass (CPB) and aortic cross clamp (ACC) time. As described by others, operation times were divided into time of CPB and ACC, which were dichotomised into $\geq 130 \mathrm{~min}$ vs. $\leq 130 \mathrm{~min}$ and $\geq 95 \mathrm{~min}$ vs. $\leq 95$ min respectively $[9,21]$.

\subsection{Clinical outcomes}

Clinical outcomes were; 1) duration of mechanical ventilation and 2) PICU-LOS following cardiac surgery. Definitions for prolonged mechanical ventilation (MV) was $\geq 2$ days (reintubation included) and prolonged PICU-LOS was $\geq 4$ days, based on the mean length of stay in PICU (United Kingdom) [22].

\subsection{Statistical analysis}

A power calculation was completed using results from Lee et al. [14] who considered the use of phase angle in critically ill adults. Based on these results of variance of phase angle in critically ill adults, it was estimated that a total of 100 patients will be required allowing for a $95 \%$ power to detect a phase angle difference of $1.2 \pm 1.0$.

SPSS version 20 (Chicago, IL) was used for statistical analysis. Associations between BIS measures, phase angle and anthropometry (HAZ) with clinical outcomes of MV and PICU-LOS were investigated. Further to this, in order to determine a potential cut off values for phase angle measures at baseline, day 0,2 and baseline a priori cut-off values were determined using receiver operator curves (ROCs) as described by Visser et al. [9]. ROCs were drawn for 10th, 20th, 30th, 40th, and 50th percentile of phase angle at baseline, post-operative day 0 , day 2 and at hospital discharge and associations with MV duration and PICU-LOS.

Area under the curves (AUC) were calculated for phase angle at baseline, post-operative day 0 , day 2 and at hospital discharge to determine cut-off value accuracy as an indicator of MV and PICULOS. The ideal phase angle cut off values for MV and PICU-LOS at each measurement time point were chosen based on the highest AUC and a p-value $<0.05$.

As the data was normally distributed parametric tests were used. Once the ideal low phase angle cut-off for had been determined, associations between a low phase angle and moderate malnutrition (HAZ) and PICU-LOS and MV duration were assessed. Chi square test or t-test was used to investigate differences between continuous variables of phase angle at baseline, postoperative day 0 , day 2 and at the time of hospital discharge for 
the various groups; PICU-LOS $\leq 4$ days and $\geq 4$ days, MV $\leq 2$ days and $\geq 2$ days, in addition to $\mathrm{HAZ} \leq-2$ and $\geq-2$, ACC, and $\mathrm{CPB}$.

Univariate logistic regression analyses were used to further investigate relationships between anthropometry (HAZ) and phase angle cut offs with MV and PICU-LOS stay. Odds ratio (OR) with a 95\% CI were calculated with MV and PICU-LOS, as dependent variables and HAZ and phase angle cut-offs at each of the time points as independent variables. If the value from these models had a pvalue $\leq 0.05$ in the univariate analyses, these variables were entered into a multivariate regression model, adjusted for age, PIMS-2 score, RACHS- 1 and operative procedure, CPB and ACC. A p value of $<0.05$ was considered statistically significant. Values are shown as mean and standard deviation.

\section{Results}

\subsection{Study population and nutritional status}

We prospectively enrolled 122 children; 2 children died during the post-operative period and 3 had BIS measurements rejected. Thus, we performed data analysis on the data from 117 children. Phase angle measures were completed in 117 children at 4 time points; with baseline before surgery $(n=109)$, post-operative day $0(n=100)$ and post-operative day $2(n=95)$ and before discharge from hospital $(n=60)$ subject to clinical circumstances. $61 \%$ were males and 39\% were females respectively, further demographic data are summarised and shown in Table 1. Nutritional status was evaluated pre-operatively; moderate malnutrition was defined as height-for-age $Z$ score (HAZ) $\leq-2 ; 28.5 \%$ of infants, $20.6 \%$ of children met the criteria. We recognized that children with genetic

Table 1

Baseline characteristics values.

\begin{tabular}{lll}
\hline Variables & $\mathrm{N}$ & Characteristics \\
\hline Gender & 117 & \\
Female & 46 & $39 \%$ \\
Male & 71 & $61 \%$ \\
Age (months) & 117 & $44.3 \pm 56$ \\
Weight (kg) & 117 & $15.5 \pm 15.4$ \\
Height (cm) & 117 & $92.2 \pm 90$ \\
Weight for age z score & 117 & $-1.1 \pm 1.6$ \\
Height for age z score & 117 & $-0.9 \pm 1.4$ \\
Body mass index z score & 117 & $-0.6 \pm 1.6$ \\
RACHS-1 & 117 & $2.7 \pm 0.8$ \\
1 & 4 & $3 \%$ \\
2 & 37 & $25 \%$ \\
3 & 55 & $52 \%$ \\
4 & 20 & $13 \%$ \\
5 & 1 & $7 \%$ \\
Paediatric index mortality score (PIM2) & 115 & $2.1 \pm 3$ \\
Aortic cross clamp (ACC) time min & 90 & $81.3 \pm 47.2$ \\
ACC $\geq$ 95 min & 31 & $34 \%$ \\
Cardiopulmonary bypass (CBG) time min & 100 & $125.2 \pm 61.6$ \\
CBG $\geq 130$ min & 40 & $40 \%$ \\
Mortality n (\%) & 2 & $1.6 \%$ \\
Albumin g/dl & 55 & $37 \pm 7.7$ \\
C-reactive protein g/l & 52 & $31.9 \pm 52.3$ \\
Lactate & 37 & $2.1 \pm 1.2$ \\
Glucose mmol/l & 37 & $9.9 \pm 11$ \\
Dopamine mcg/min & 42 & $4.8 \pm 2.7$ \\
Nor-adrenaline mcg/min & 7 & $0.05 \pm 0.04$ \\
Adrenaline mcg/min & 6 & $0.08 \pm 0.03$ \\
Milrinone mcg/min & 50 & $0.5 \pm 0.2$ \\
Day 0 fluid balance ml & 101 & $68 \pm 351$ \\
Day 2 fluid balance ml & 56 & $232 \pm 351$ \\
Phase angle baseline & 109 & $4.2 \pm 1.3$ \\
Phase angle day 0 & 100 & $3.1 \pm 1.2$ \\
Phase angle day 2 & 95 & $3.6 \pm 1.7$ \\
Phase angle discharge & $60.8 \pm 1.1$ \\
\hline
\end{tabular}

(Mean \pm standard deviation). syndromes will have altered patterns of growth, be more medically fragile and as result often excluded from studies. Only $n=6$ children ( $6 \%$ of the total population studied) had either 22q.11 deletion or T21. Their mean HAZ score was $-1.10 \pm 2.9$ (range: $-3.42-1.24$ ), their mean length of PICU stay was $3.1 \pm 1.7$ and phase angles recorded were as follows; baseline $3.0 \pm 0.5$, day $1: 2.1 \pm 0.8$, day $2: 2.3 \pm 0.9$.

\subsection{Relationship between phase angle and measures of nutritional status}

There were significant positive correlations between phaseangle and preoperative WAZ, HAZ at baseline $(\mathrm{n}=109, \mathrm{r}=0.2$, $\mathrm{p}=0.03)$, day $0(\mathrm{n}=100, \mathrm{r}=0.2, \mathrm{p}=0.02)$ and $2(\mathrm{n}=95, \mathrm{r}=0.2$, $\mathrm{p}=0.04)$ but not at discharge $(\mathrm{n}=60, \mathrm{r}=0.22, \mathrm{p}=0.3)$ and WAZ at baseline ( $\mathrm{n}=109, \mathrm{r}=0.3, \mathrm{p}=0.03)$, day $0(\mathrm{n}=100, \mathrm{r}=0.3$, $\mathrm{p}=0.02)$ and $2(\mathrm{n}=95, \mathrm{r}=0.3, \mathrm{p}=0.02)$ but not at discharge ( $\mathrm{n}=60, \mathrm{r}=0.02, \mathrm{p}=0.3$ ). There were no significant associations with $\mathrm{WHZ}$ and measures of phase angle.

The strength of these relationships were tested further using Cohen's kappa correlation. Cohen's kappa was performed determine if there was an agreement between phase angle at baseline, day 0 , day 2 and discharge with height for age and body mass index for age. There was moderate agreement between height for age $z$ scores and phase angle at baseline and discharge, but not on day 0 and day 2. With regards to weight for height $\mathrm{z}$ scores there is moderate agreement between phase angle at baseline, but not at any other time point. There was no agreement with phase angle at weight for age $\mathrm{z}$ score at any time point.

\subsection{Optimal low phase angle cut-off values}

The ROC curves at the various times points revealed that phase angle at the 40th percentile at day $0(2.6, \mathrm{p}=0.03)$, 30th percentile at day $2(2.7, \mathrm{p}=0.03)$ and 50th centile $(3.4, \mathrm{p}=0.01)$ at hospital discharge was the highest predictive accuracy of adverse clinical outcomes with respect to MV. For PICU-LOS the percentiles with the highest accuracy levels for phase angle were as follows: 20th percentile at baseline $\left(2.9^{\circ}, \mathrm{p}=0.008\right)$, 50th percentile on day $0\left(2.9^{\circ}, \mathrm{p}=0.04\right)$, 30th percentile on day $2\left(2.7^{\circ}, \mathrm{p}<0.0001\right)$ and 20th percentile at the time of discharge $\left(2.7^{\circ}, \mathrm{p}=0.03\right)$. A phase angle of $\leq 2.7^{\circ}$ was present in $9 \%$ of children at baseline $43 \%$ (day 0 ), $29.8 \%$ (day 2 ) and $11.6 \%$ children respectively.

\subsection{Relationship between phase angle and clinical outcomes}

Children with a longer length of PICU $>4$ days had significantly lower phase angle measures on day 0,2 and discharge compared to children whose PICU-LOS was $<4$ days (Table 2). At baseline no significant difference between the groups were observed (Fig. 2). Children with a longer length of PICU $>4$ days had significantly higher RACHS-1, aortic cross-clamp, cardiac bypass time, vasoactive inotrope score, lactate and C-reactive protein compared to those with a PICU $<4$ days. There were no significant differences in lactate, fluid balance day 0 or day 2 .

Out of those with a phase angle of $<2.7^{\circ}(\mathrm{n}=28)$ on day 2 only 8 children had a HAZ $<-2$. The mean HAZ of children with a phaseangle of $\leq 2.7^{\circ}$ was $-1.8 \pm 1.5$ compared to than those in the moderate malnutrition group HAZ where the mean HAZ was $-2.9 \pm 0.9(p=0.002)$. Further comparison showed there was a significant difference in PICU-LOS of children with a HAZ $<-2$ compared to those with a phase angle $>2.7(4.5 \pm 3.3$ vs. $2.5 \pm 0.9)$ $\mathrm{p}=0.002$, as well as between those children with a phase angle $<2.7$ compared to phase angle $>2.7(6.0 \pm 0.8$ vs. $2.5 \pm 0.9)$ $\mathrm{p}<0.0001$. There was no significant difference in PICU-LOS in those who had a HAZ $>-2$ compared to a phase angle $>2.7$ (3.0 \pm 1.5 vs. 
Table 2

Phase angle in children with a length of PICU-LOS $>4$ days compared to children with a PICU-LOS $<4$ days.

\begin{tabular}{llll}
\hline Phase angle & PICU LOS $<4$ days & PICU LOS $>4$ days & p value \\
\hline Baseline & $4.0 \pm 1.1$ & $3.8 \pm 1.4$ & Ns \\
Day 0 & $3.2 \pm 1.2$ & $2.5 \pm 1.4$ & 0.005 \\
Day 2 & $3.8 \pm 1.8$ & $2.7 \pm 0.9$ & 0.0002 \\
Discharge & $3.9 \pm 1.0$ & $3.3 \pm 0.7$ & 0.03 \\
\hline
\end{tabular}

$2.5 \pm 0.9$ ) or between those who had a HAZ $<-2$ compared phase angle $<2.7(4.5 \pm 3.3$ vs. $6.0 \pm 0.8)$.

\subsection{A low phase angle and associations with MV and PICU-LOS}

The relationships between phase angle and HAZ on clinical outcomes; MV and PICU-LOS were explored using regression analyses. In the unadjusted analysis shortness (HAZ $\leq-2)$ was associated with an increased PICU-LOS $(\mathrm{p}=0.008)$ whilst a low phaseangle $\left(<2.7^{\circ}\right)$ on day 2 was associated with longer PICU-LOS $(\mathrm{p}<0.0001)$. A phase angle cut off value of $\leq 2.6^{\circ}$ on day 0 was associated with increased MV $(\mathrm{p}=0.01)$. When the model was adjusted for age, length of surgical procedure, a phase angle of $<2.7^{\circ}$ on day 2 OR $0.3 ; 0.3-0.6, \mathrm{p}=0.01$ ) and $\mathrm{HAZ} \leq-2$ OR 4.5 ; $1.1-18, \mathrm{p}=0.03$ ) remained significantly associated with an increased PICU-LOS with a predictive accuracy of $81.7 \%$. A phase angle cut off $<2.6^{\circ}$ on day 0 was not associated with an increased $\mathrm{MV}$, although there was a significant association with $\mathrm{HAZ} \leq-2$, OR $0.3(0.3-0.6, p=0.01)$ with a predictive accuracy of $84.3 \%$ (Table 3 ).

\section{Discussion}

In this prospective study we show that persistent malnutrition and a low phase angle $\left(<2.7^{\circ}\right)$ measured on day 2 in children with
CHD was associated with an increased risk of PICU-LOS. This association remained after adjusting for age, risk factors and length of operative procedure (AAC, CBP). However, only 8 children out of 28 who had a phase angle of $<2.7^{\circ}$ on day 2 had a HAZ $<-2$. This suggests that adding BIS to pre-operative anthropometry will increase precision when predicting ICU LOS in these patients (see Table 4).

Our findings are in line with findings from other studies, which report that BIS-phase angle is a prognostic marker for poorer clinical outcome in adults in critical illness [14], chronic renal failure [23], oncology [4,24,25], human immunodeficiency virus syndrome [26], liver disease [27] and the elderly [19]. Phase angle has been shown to correlate with various indicators of health and nutritional status. This is the first time to our knowledge a predictive value for phase angle have been associated with poor outcomes in a paediatric CHD cohort following cardiac surgery. Although there are limitations to this finding, particularly as there is a paucity of data regarding the use of BIS in congenital heart disease [10]. As such these results will need to be confirmed using a larger cohort of children with CHD.

Low phase angle values have been shown to be predictive of functional reserves $[4,6,7]$ and resilience in a variety of other clinical conditions [12-14] and have been shown to be related to nutritional status in children [15]. As to be expected our cut off value was significantly lower than those described in healthy adult individuals, which usually ranges between $5^{\circ}$ and $7^{\circ}$, with lower values reported in females and children [8]. As BIS can easily be used at the bedside and does not require patient participation, there is increasing interest in trying to develop standardized cut-off reference values e.g. $\mathrm{z}$ scores allowing for the comparison of values amongst patients differing in gender, age and disease state in order to better identify those patients with low functional status and subsequent increased risk of poorer functional outcomes. One of the challenges in applying a single defined cut-off for phase angle in clinical practice

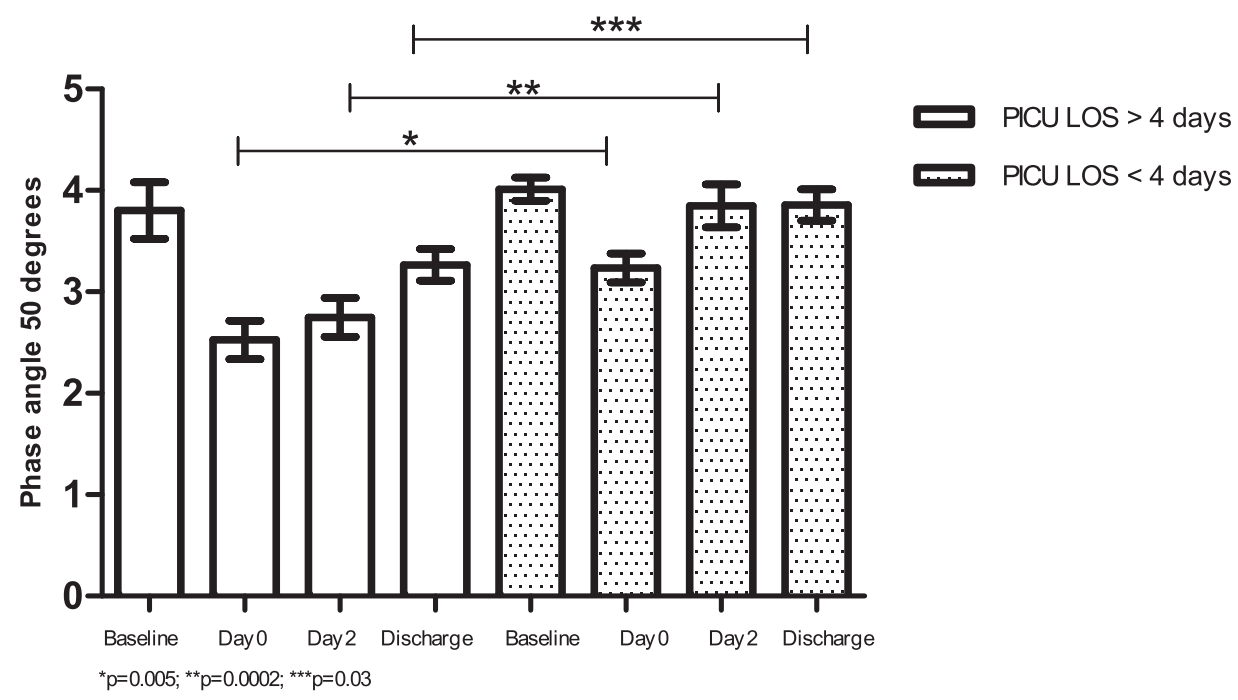

Fig. 2. Phase angle in children with a length of PICU-LOS $>4$ days $(n=28)$ compared to children with a PICU-LOS $<4$ days $(n=89)$

Table 3

Optimal phase angle cut off values for duration of mechanical ventilation and PICU-LOS.

\begin{tabular}{|c|c|c|c|c|c|c|}
\hline & \multicolumn{3}{|c|}{ Mechanical ventilation } & \multicolumn{3}{|l|}{ PICU-LOS } \\
\hline & Percentile & Cut off value & Area under curve, $95 \% \mathrm{CI}$ & Percentile & Cut off value & Area under curve, $95 \% \mathrm{CI}$ \\
\hline Baseline phase angle & NS & & & 20th & 2.9 & $0.7,0.6-0.8, p=0.008$ \\
\hline Post-op day 0 phase angle & 40th & 2.6 & $0.6,0.5-0.8, p=0.03$ & 50th & 2.9 & $0.6,0.5-0.7, p=0.04$ \\
\hline Post-op day 2 phase angle & 30th & 2.7 & $0.6,0.5-0.8, p=0.03$ & 30th & 2.7 & $0.8,0.7-0.9, \mathrm{p}<0.0001$ \\
\hline Discharge from hospital & 50th & 3.4 & $0.7,0.6-0.8, p=0.01$ & 20th & 2.7 & $0.8,0.6-1.0, p=0.03$ \\
\hline
\end{tabular}


Table 4

Regression analysis of a low phase angle and HAZ $<-2$ with duration of mechanical ventilation and PICU-LOS.

\begin{tabular}{|c|c|c|c|c|c|c|c|}
\hline & & \multicolumn{3}{|c|}{ Univariate } & \multicolumn{3}{|c|}{ Multivariate ${ }^{*, * *}$} \\
\hline & & OR & $95 \% \mathrm{CI}$ & $\mathrm{p}$ & OR & $95 \% \mathrm{CI}$ & $\mathrm{p}$ \\
\hline \multirow[t]{2}{*}{ PICU-LOS } & $\begin{array}{l}\text { Phase angle day } 2 \\
<2.7^{*}\end{array}$ & 7.8 & $2.7-22.45$ & 0.001 & 4.5 & $1.1-18$ & 0.03 \\
\hline & $\mathrm{HAZ}<2^{* *}$ & 1.8 & $1.1-2.7$ & 0.008 & 5.2 & $1.1-26.1$ & 0.04 \\
\hline \multirow[t]{2}{*}{ Mechanical ventilation } & $\begin{array}{l}\text { Phase angle day } 0 \\
2.6\end{array}$ & 4.1 & $1.3-12.4$ & 0.01 & 0.3 & $0.8-1.4$ & 0.1 \\
\hline & $\mathrm{HAZ}<2$ & 0.5 & $0.3-0.8$ & 0.001 & 0.1 & $0.3-0.6$ & 0.01 \\
\hline
\end{tabular}

$\mathrm{p} \leq 0.05$ Multivariate analyses; *model 1 : PA $\leq 2.7$, ** model 2 : HAZ $<-2$ adjusted for age, risk scores (RACHS-1, PIMS2), duration of operative procedures (AAC, CBP).

is that such cut-offs are study specific, due to differences in study population, device and approach to determining a value for phase angle. Therefore, like others, our cut-off should only be considered in the context of the conditions and population used in this study. In order to strengthen the application of this technology the utility of phase angle should be studied in a larger cohort across multiple centres, with the aim of validating the cut of values and creating reference $z$ scores for phase angle to be used in this context [8].

We also found a proportion of children with CHD had moderate malnutrition prior to cardiac surgery (28\% infants and $20.6 \%$ children). We have previously shown that $28.4 \%$ of infants with $\mathrm{CHD}$ requiring surgery are chronically malnourished with a height-forage $\mathrm{z}$ score $(\mathrm{HAZ}) \leq-2$, a similar finding described in other centres including Australia, Nigeria, India and the USA [28-34]. The causes of growth failure in this population are multifactorial and include intrauterine factors, increased post-natal metabolic requirements, feeding difficulties and peri-operative feed intolerance, compounded by the need for fluid restriction during this period $[35,36]$. Although growth restriction is widespread in children with CHD [28-34,37], the impact of poor linear growth on the perioperative clinical course and PICU-LOS has only recently been described in critically ill children [1,2].

BIS has been used in a variety of other settings to assess body composition, which in children is described as preceding changes in anthropometrical measures [4,5] and may therefore be useful in monitoring the efficacy of nutrition support [38] or changes in nutritional status during hospitalisation [19]. Children with CHD are often chronically malnourished at the time of surgery, with low age-related height and weight $\mathrm{z}$ score $[28,30,37,39]$. Moderate malnutrition is defined as a HAZ, WAZ and WHZ $\mathrm{z}$ score of more than 2 standard deviations below the reference population mean [37]. Despite improvements in the surgical and perioperative care of infants with $\mathrm{CHD}$, those with growthrestriction continue to have significant morbidity [40]. Infants with a WAZ score below -2 at the time of surgery and impaired weight gain post-surgery, have a significantly higher mortality at 3 and 12 months of age $[39,41]$.

A HAZ $\leq-2$ should be regarded as a dynamic process of "persistent malnutrition" representing insufficient intake of macroand micronutrients to support adequate tissue deposition and growth [42]. Persistent malnutrition in children is associated with poor physiological, immunological and metabolic control and a lack of functional reserve, reflected by lower body cell mass and functional lean tissue, thymic size and sodium pump function, metabolic control and renal concentrating ability [42], which is likely to result in poorer post-operative resilience. Those with a phase angle of $<2.7^{\circ}$ had the longest PICU-LOS $(6.0 \pm 0.8$ days $)$ compared to those who had a low HAZ $<-2(4.5 \pm 3.3$ days $)$ and although the difference was not significant, the PICU-LOS was longer in the phase angle of $<2.7^{\circ}$ group, suggesting there may be early cellular changes and using weight or height alone may not identify all of those at risk. Our results suggest that it is practical to perform perioperative BIS measurements of phase angle in children with CHD following cardiac surgery. $[4,5,12,43]$.

\section{Conclusion}

Persistent malnutrition was common in children undergoing surgery for CHD, and in this study was associated with poorer postoperative resilience. Whilst we found that preoperative HAZ is predictive of a longer PICU stay, post-operative BIS-phase angle measurement improved the accuracy of prediction, which may help us to identify children at the highest risk of prolonged PICU stay, compared to using pre-operative anthropometry alone.

\section{Funding}

The study was supported by NIHR Southampton Biomedical Research Centre Commercial \& Enterprise Incubator Fund (Study number: RHM CH10742) in collaboration with an educational grant from Nutricia, UK. LVM was supported by a post-doctoral fellowship award from NIHR Health Education England (Wessex).

\section{Statement of authorship}

All authors have made substantial contributions to all of the following areas of this manuscript: LVM, CN, KS, JPV, SAW, AM participated in the design of the study. LVM, CJ carried out the data collection. LVM, MJ, JVP, SAW, RWM completed the data and statistical analyses and drafted the manuscript. All authors edited, read and approved the final manuscript.

\section{Conflict of interest}

None noted.

\section{Acknowledgements}

Specialist Cardiac Liaison and Practice Nurses; Colette Cochran, Gill Harte, Doreen Macfail, Katy Simons, Carolyn Boyles for their assistance in identifying potential recruits. Medical students; Kate Allen-McGraw and Richa Dhar for their assistance. To all of the children and their families for agreeing to participate in the study and NIHR Southampton Biomedical Research Centre and Nutricia (UK) for their support.

\section{References}

[1] Grippa RB, Silva PS, Barbosa E, Bresolin NL, Mehta NM, Moreno YM. Nutritional status as a predictor of duration of mechanical ventilation in critically ill children. Nutrition 2017 Jan;33:91-5.

[2] Bechard LJ, Duggan C, Touger-Decker R, Parrott JS, Rothpletz-Puglia P, ByhamGray L, et al. Nutritional status based on body mass index is associated with morbidity and mortality in mechanically ventilated critically ill children in the PICU. Crit Care Med 2016 Aug;44(8):1530-7. 
[3] Bagri NK, Jose B, Shah SK, Bhutia TD, Kabra SK, Lodha R. Impact of malnutrition on the outcome of critically ill children. Indian J Pediatr 2015 Jul;82(7):601-5.

[4] Farias CL, Campos DJ, Bonfin CM, Vilela RM. Phase angle from BIA as a prognostic and nutritional status tool for children and adolescents undergoing hematopoietic stem cell transplantation. Clin Nutr Edinb Scotl 2013 Jun;32(3):420-5.

[5] Pileggi VN, Monteiro JP, Margutti AV, Camelo Jr JS. Prevalence of child malnutrition at a university hospital using the World Health Organization criteria and bioelectrical impedance data. Braz J Med Bio Res 2016 Mar;49(3).

[6] Selberg O, Selberg D. Norms and correlates of bioimpedance phase angle in healthy human subjects, hospitalized patients, and patients with liver cirrhosis. Eur J Appl Physiol 2002 Apr;86(6):509-16.

[7] Baumgartner RN, Chumlea WC, Roche AF. Bioelectric impedance phase angle and body composition. Am J Clin Nutr 1988 Jul;48(1):16-23.

[8] Norman K, Stobaus N, Pirlich M, Bosy-Westphal A. Bioelectrical phase angle and impedance vector analysis-clinical relevance and applicability of impedance parameters. Clin Nutr (Edinburgh, Scotland) 2012 Dec;31(6):854-61.

[9] Visser M, van Venrooij LM, Wanders DC, de Vos R, Wisselink W, van Leeuwen PA, et al. The bioelectrical impedance phase angle as an indicator of undernutrition and adverse clinical outcome in cardiac surgical patients. Clin Nutr (Edinburgh, Scotland) 2012 Dec;31(6):981-6.

[10] Shime N, Ashida H, Chihara E, Kageyama K, Katoh Y, Yamagishi M, et al. Bioelectrical impedance analysis for assessment of severity of illness in pediatric patients after heart surgery. Crit Care Med 2002 Mar;30(3):518-20.

[11] Azevedo ZM, Moore DC, de Matos FA, Fonseca VM, Peixoto MV, GasparElsas MI, et al. Bioelectrical impedance parameters in critically ill children: importance of reactance and resistance. Clin Nutr (Edinburgh, Scotland) 2013 Oct;32(5):824-9.

[12] Kyle UG, Soundar EP, Genton L, Pichard C. Can phase angle determined by bioelectrical impedance analysis assess nutritional risk? A comparison between healthy and hospitalized subjects. Clin Nutr (Edinburgh, Scotland) 2012 Dec;31(6):875-81.

[13] da Silva TK, Berbigier MC, Rubin Bde A, Moraes RB, Correa Souza G, Schweigert Perry ID. Phase angle as a prognostic marker in patients with critical illness. Nutr Clin Pract 2015 Apr;30(2):261-5.

[14] Lee Y, Kwon O, Shin CS, Lee SM. Use of bioelectrical impedance analysis for the assessment of nutritional status in critically ill patients. Clin Nutr Res 2015 Jan;4(1):32-40.

[15] Nagano M, Suita S, Yamanouchi T. The validity of bioelectrical impedance phase angle for nutritional assessment in children. J Pediatr Surg 2000 Jul;35(7):1035-9.

[16] WHO. WHO Anthro (version 3.2.2, January 2011). 2015.

[17] WHO. WHO AnthroPlus. 2015.

[18] WHO. Growth reference 5-19 years: BMI-for-age (5-19 years). 2015. Available from: http://www.who.int/growthref/who2007_bmi_for_age/en/.

[19] Kyle UG, Earthman CP, Pichard C, Coss-Bu JA. Body composition during growth in children: limitations and perspectives of bioelectrical impedance analysis. Eur J Clin Nutr 2015 Dec;69(12):1298-305.

[20] Jenkins KJ, Gauvreau K, Newburger JW, Spray TL, Moller JH, Iezzoni LI Consensus-based method for risk adjustment for surgery for congenital heart disease. J Thorac Cardiovasc Surg 2002 Jan;123(1):110-8.

[21] Li S, Krawczeski CD, Zappitelli M, Devarajan P, Thiessen-Philbrook H, Coca SG, et al. Incidence, risk factors, and outcomes of acute kidney injury after pediatric cardiac surgery: a prospective multicenter study. Crit Care Med 2011 Jun;39(6):1493-9.

[22] PICANET. PICANET annual report 2015. 11th December 2015. Available from: http://www.picanet.org.uk/Audit/Annual-Reporting/PICANet_2015_Annual_ Report_Summary.pdf.

[23] Maggiore O Nigrelli S, Ciccarelli C, Grimaldi C, Rossi GA, Michelassi C. Nutritional and prognostic correlates of bioimpedance indexes in hemodial ysis patients. Kidney Int $1996 \mathrm{Dec} ; 50(6): 2103-8$.

[24] Toso S, Piccoli A, Gusella M, Menon D, Bononi A, Crepaldi G, et al. Altered tissue electric properties in lung cancer patients as detected by bioelectric impedance vector analysis. Nutrition 2000 Feb;16(2):120-4.
[25] Gupta D, Lammersfeld CA, Vashi PG, King J, Dahlk SL, Grutsch JF, et al. Bioelectrical impedance phase angle as a prognostic indicator in breast cancer. BMC Cancer 2008;8:249.

[26] Schwenk A, Beisenherz A, Romer K, Kremer G, Salzberger B, Elia M. Phase angle from bioelectrical impedance analysis remains an independent predictive marker in HIV-infected patients in the era of highly active antiretroviral treatment. Am J Clin Nutr 2000 Aug;72(2):496-501.

[27] Ruiz-Margain A, Macias-Rodriguez RU, Duarte-Rojo A, Rios-Torres SL, Espinosa-Cuevas A, Torre A. Malnutrition assessed through phase angle and its relation to prognosis in patients with compensated liver cirrhosis: a prospective cohort study. Dig Liver Dis 2015 Apr;47(4):309-14.

[28] Toole BJ, Toole LE, Kyle UG, Cabrera AG, Orellana RA, Coss-Bu JA. Perioperative nutritional support and malnutrition in infants and children with congenital heart disease. Congenit Heart Dis 2014 Jan-Feb;9(1):15-25.

[29] Correia Martins L, Lourenco R, Cordeiro S, Carvalho N, Mendes I, Loureiro M, et al. Catch-up growth in term and preterm infants after surgical closure of ventricular septal defect in the first year of life. Eur J Pediatr 2016 Apr;175(4):573-9.

[30] Costello CL, Gellatly M, Daniel J, Justo RN, Weir K. Growth restriction in infants and young children with congenital heart disease. Congenit Heart Dis 2015 Sep-Oct;10(5):447-56.

[31] Okoromah CA, Ekure EN, Lesi FE, Okunowo WO, Tijani BO, Okeiyi JC. Prevalence, profile and predictors of malnutrition in children with congenital heart defects: a case-control observational study. Arch Dis Child 2011 Apr;96(4): 354-60. PubMed PMID: 21266339.

[32] Vaidyanathan B, Nair SB, Sundaram KR, Babu UK, Shivaprakasha K, Rao SG, et al. Malnutrition in children with congenital heart disease (CHD) determinants and short term impact of corrective intervention. Indian Pediatr 2008 Jul; 45(7):541-6.

[33] Blasquez A, Clouzeau H, Fayon M, Mouton JB, Thambo JB, Enaud R, et al. Evaluation of nutritional status and support in children with congenital heart disease. Eur J Clin Nutr 2016 Apr;70(4):528-31.

[34] Ravishankar C, Zak V, Williams IA, Bellinger DC, Gaynor JW, Ghanayem NS, et al. Association of impaired linear growth and worse neurodevelopmental outcome in infants with single ventricle physiology: a report from the pediatric heart network infant single ventricle trial. J Pediatr 2013 Feb;162(2). 250 e2-256 e2.

[35] Medoff-Cooper B, Ravishankar C. Nutrition and growth in congenital heart disease: a challenge in children. Curr Opin Cardiol 2013 Jan;28(2):122-9.

[36] Williams RV, Ravishankar C, Zak V, Evans F, Atz AM, Border WL, et al. Birth weight and prematurity in infants with single ventricle physiology: pediatric heart network infant single ventricle trial screened population. Congenit Heart Dis 2010 Mar-Apr;5(2):96-103.

[37] Marino LV, Magee A. A cross-sectional audit of the prevalence of stunting in children attending a regional paediatric cardiology service. Cardiol Young 2015 Sep 11:1-3.

[38] Martinez EE, Bechard LJ, Smallwood CD, Duggan CP, Graham RJ, Mehta NM. Impact of individualized diet intervention on body composition and respiratory variables in children with respiratory insufficiency: a pilot intervention study. Pediatr Crit Care Med 2015 Jul;16(6):e157-64.

[39] Mitting R, Marino L, Macrae D, Shastri N, Meyer R, Pathan N. Nutritional status and clinical outcome in postterm neonates undergoing surgery for congenital heart disease. Pediatr Crit Care Med 2015 Jun;16(5):448-52.

[40] Oster ME, Ehrlich A, King E, Petit CJ, Clabby M, Smith S, et al. Association of interstage home monitoring with mortality, readmissions, and weight gain: a multicenter study from the national pediatric cardiology quality improvement collaborative. Circulation 2015 Aug 11;132(6):502-8.

[41] Eskedal LT, Hagemo PS, Seem E, Eskild A, Cvancarova M, Seiler S, et al. Impaired weight gain predicts risk of late death after surgery for congenital heart defects. Arch Dis Child 2008 Jun;93(6):495-501.

[42] Golden MH. Proposed recommended nutrient densities for moderately malnourished children. Food Nutr Bull 2009 Sep;30(Suppl. 3):S267-342.

[43] Kyle UG, Genton L, Pichard C. Low phase angle determined by bioelectrical impedance analysis is associated with malnutrition and nutritional risk at hospital admission. Clin Nutr (Edinburgh, Scotland) 2013 Apr;32(2):294-9. 